\title{
Improvement of Thermal Stability via Outer-Loop Ion Pair Interaction of Mutated T1 Lipase from Geobacillus zalihae Strain T1
}

\author{
Rudzanna Ruslan ${ }^{1}$, Raja Noor Zaliha Raja Abd. Rahman ${ }^{1,2, *}$, Thean Chor Leow ${ }^{1,2}$, \\ Mohd Shukuri Mohamad Ali ${ }^{1}$, Mahiran Basri ${ }^{2,3}$ and Abu Bakar Salleh ${ }^{1,2}$
}

1 Enzyme and Microbial Technology Laboratory, Faculty of Biotechnology and Biomolecular Sciences, Universiti Putra Malaysia, 43400 UPM Serdang, Selangor, Malaysia;

E-Mails: rudzanna@gmail.com (R.R.); adamleowupm1@gmail.com (T.C.L.); shukuri12@gmail.com (M.S.M.A.); abubakar67@yahoo.com (A.B.S.)

2 Institute of Bioscience, Universiti Putra Malaysia, 43400 UPM Serdang, Selangor, Malaysia; E-Mail: mahiran@science.upm.edu.my

3 Faculty of Science, Universiti Putra Malaysia, 43400 UPM Serdang, Selangor, Malaysia

* Author to whom correspondence should be addressed; E-Mail: rnzaliha.biotech@gmail.com; Tel.: +60-389466709; Fax: +60-389430913.

Received: 8 October 2011; in revised form: 25 November 2011 / Accepted: 28 November 2011 / Published: 17 January 2012

\begin{abstract}
Mutant D311E and K344R were constructed using site-directed mutagenesis to introduce an additional ion pair at the inter-loop and the intra-loop, respectively, to determine the effect of ion pairs on the stability of T1 lipase isolated from Geobacillus zalihae. A series of purification steps was applied, and the pure lipases of T1, D311E and K344R were obtained. The wild-type and mutant lipases were analyzed using circular dichroism. The $T_{m}$ for $\mathrm{T} 1$ lipase, D311E lipase and K344R lipase were approximately $68.52{ }^{\circ} \mathrm{C}, 70.59{ }^{\circ} \mathrm{C}$ and $68.54^{\circ} \mathrm{C}$, respectively. Mutation at D311 increases the stability of T1 lipase and exhibited higher $T_{m}$ as compared to the wild-type and K344R. Based on the above, D311E lipase was chosen for further study. D311E lipase was successfully crystallized using the sitting drop vapor diffusion method. The crystal was diffracted at $2.1 \AA$ using an in-house X-ray beam and belonged to the monoclinic space group $C 2$ with the unit cell parameters $a=117.32 \AA, b=81.16 \AA$ and $c=100.14 \AA$. Structural analysis showed the existence of an additional ion pair around E311 in the structure of D311E. The
\end{abstract}


additional ion pair in D311E may regulate the stability of this mutant lipase at high temperatures as predicted in silico and spectroscopically.

Keywords: thermostable lipase; ion pair interaction; thermal stability; CD spectral analysis; lipase crystal; X-ray diffraction

\section{Introduction}

Many lipases preserve their activity at extreme conditions, such as temperature and $\mathrm{pH}$. Lipases have many industrial applications, for example in the processing of agroindustrial residues [1], leather manufacturing, detergents, and flavor production in dairy and medical applications [2]. Mostly, Bacillus lipases display diverse selectivity to the chain length of the acid, and few enzymes show positional specificity but several enzymes can be applied in pharmaceutical industry due to the enantioselectivity [3].

To meet the industrial demand, a high activity and heat-stable lipase is preferred to mediate catalysis at high temperature. Thermal stability is a major requirement for a commercial enzyme because thermal denaturation is a common cause of enzyme inactivation [4]. In the previous decade, protocols based on in vitro screening of large populations of protein variants, which are collectively known as directed evolution methods, have led to extraordinary success in altering the enzymatic properties, such as stability, affinity and selectivity of proteins [5]. Nevertheless, to improve industrial biocatalyst features, methods of chemical modification and immobilization of enzymes have been considered and chemical modifications made, such as stabilizing additives [6,7]. Furthermore, enzyme engineering via immobilization techniques is perfectly compatible with other chemical or biological approaches to improve enzyme functions [8].

Rational design has been applied in many fields of mutagenesis study. The extensive and systematic testing of each product of the executable code is needed to describe and support the importance of the research. An important point of focus is to determine which mutation will affect the stability of the mutant with respect to the wild-type. The mutants are mainly based on the development of different energy functions and are suited to compute the stability free energy changes [9,10]. In this proteomic era, the mutagenic process is constructed using many developed methods. The development of predictors is needed to study the effects of the mutation computationally before conducting experiments. These have been used in many fields of research. The molecular modeling and site-directed mutagenesis can be used to elucidate the structural basis [11]. Moreover site-directed mutagenesis, directed evolution, allows fine modification of the properties of their lipases such as introducing a new ion pair into the structure [3]. Rahman et al [12]. have shown that ion pair networks play a key role in maintaining enzymatic stability at extreme temperatures.

Most lipases contain a lid domain controlling access to the active site [13]. Lipase activity is greatly increased at the lipid-water interface which is known as interfacial activation [14]. The interaction of the enzyme with the lipid aggregates induces the displacement of the lid, which makes the active site accessible to individual substrate molecules and increases the catalytic activity [15]. Unlike T1 lipase, 
the crystal structure of BTL2 was solved in an open conformation with two molecules of triton detergent present in the active site.

Here, we report on the effect of an ion pair network on the stability of T1 lipase by introducing an additional ion pair at the inter-loop and the intra-loop. In addition, we elucidated the structure of D311E lipase to identify the additional interactions that govern the stability of this mutant.

\section{Results and Discussion}

\subsection{Rational Design of Mutant Lipases}

The crystal structure of thermostable T1 lipase (PDB ID: 2DSN) contained the metal ions $\mathrm{Ca}^{2+}$, $\mathrm{Zn}^{2+}, \mathrm{Cl}^{-}$and $\mathrm{Na}^{+}$as well as chain A and chain B in asymmetry [16]. The structure solved in closed conformation with the active site buried under a long lid-helix. Based on this crystal structure, the mutant D311E lipase and K344R lipase were designed to locate the inter-loop and intra-loop interactions, respectively, by introducing additional non-bonded interactions. These positions were chosen to compare and study the effect of the ion pair and the hydrogen bond that was formed after mutation.

Figure 1 shows the ion pair and hydrogen bond interactions that may be introduced into the D311E lipase and K344R lipase structure and were analyzed using Swiss PDB Viewer. The images were generated using POV-Ray in order to obtain high quality images. This interaction indicated that ion pair interactions were located at exposed parts of the inter-loops and the intra-loops of the protein. More ion pairs were observed in D311E lipase compared to those in K344R lipase. These interactions may provide stability to the $\mathrm{D} 311 \mathrm{E}$ lipase structure due to the high flexibility of the outer portion of the protein compared to that of the inner portion of the protein. In addition, this method was used in previous research that described the success of the rational design approach in improving the stability of the mutant [17-19].

Figure 1. Protein tailoring of D311E lipase forming inter-loops networking, whereby K344R forming intra-loop networking. The green dash line indicated ion pair and hydrogen bond interactions.

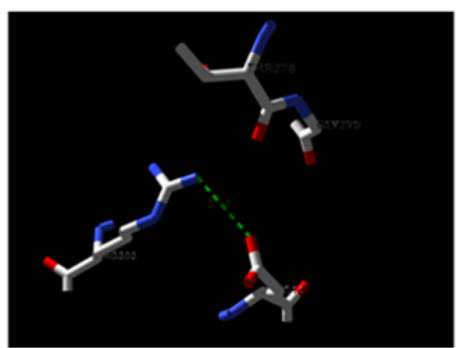

1 salt-bridge

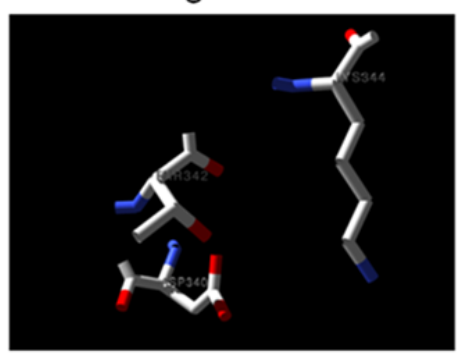

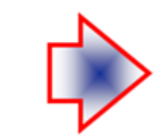

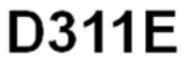

(Inter-loops)

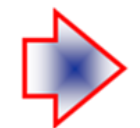

K344R

(Intra-loop)

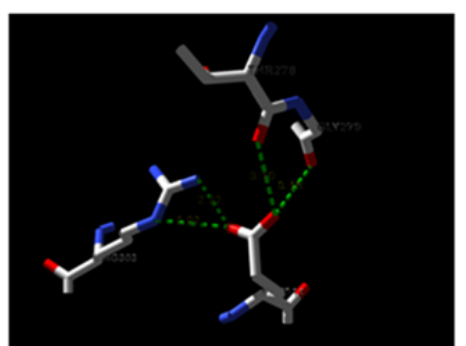

2 salt-bridge, $2 \mathrm{H}$-bonds

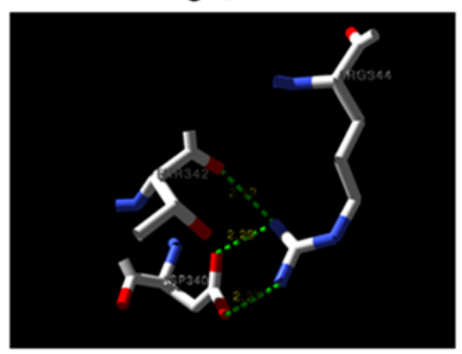

2 salt-bridge, $1 \mathrm{H}$-bond 


\subsection{Prediction of Protein Stability Changes upon Point Mutation}

I-Mutant 2.0 predictions were performed using the protein structure or, more importantly, from the protein sequence. In general, an exposed residue with an increased stability is free to mutate compared to a partially buried residue.

Table 1, summarizes the prediction result of the protein stability that changes upon point mutation. The D311E protein sequence was submitted to I-Mutant 2.0 software as an input file. This software predict minima at the verified recombination sites-supporting the assumption to cut at less sensitive regions (high acceptance of substitutions) [20]. The stability of D311E lipase was expected to increase because we obtained a positive free energy change (DDG) value, which increased the stability. The substitution of D311 to E311 improved the structural properties by introducing the interactions of the additional ion pair. The additional ion pair strengthened the structural interaction of the D311E lipase.

Table 1. Summary of prediction energy, based on single point of mutation.

\begin{tabular}{cccc}
\hline Mutant & Stability & $\begin{array}{c}\text { Reliability Index } \\
\text { (kcal/mole) }\end{array}$ & $\begin{array}{c}\text { Relative } \\
\text { Solvent Accessibility Area (\%) }\end{array}$ \\
\hline D311E & Increase & 7.0 & 67.3 \\
K344R & Decrease & 4.0 & 39.9 \\
\hline
\end{tabular}

The RI value (Reliability Index) is computed when the sign of the stability change is predicted and evaluated based on the output of the SVM (support vector machine) at $O$ as RI $=20$ times to absorbance (0-0.5) [21]. The RI of this protein was $7.0 \mathrm{kcal} / \mathrm{mole}$. A high RI is important to interpret the output data, as it indicates the probability that the structure will not fail to perform stabilizing functions [1]. The predicted optimal Relative Solvent Accessible Area (RSA) value of D311E lipase was $67.3 \%$. The RSA value is calculated using the DSSP program when the prediction is based on the enzymatic structure, by dividing the accessible surface area value of the mutated residue by the free residue surface [22]. DSSP program has also been used by [23] Capriotti et al. to calculate the RSA of the $21^{\text {st }}$ element vector of the protein structural environment. With those values, we expect that this prediction is a good indicator and useful in studies on the inter-relationships of D311E lipase structure and energetic measurements.

\subsection{Circular Dichroism Analysis}

The CD spectra of D311E lipase were analyzed as a function of temperature at $220 \mathrm{~nm}$. The wavelength $220 \mathrm{~nm}$ was set to monitor the transition of $\alpha$-helices to disordered structures because they exhibited characteristic signals at this wavelength. The purified lipases of T1, D311E and K344R were expressed using the pGEX/T1S vector and purified at 4.6-fold, 1.98-fold and 4.0-fold, respectively.

Figure 2 shows that the analysis of the unfolded protein of D311E lipase compared with another mutant, K344R lipase and its native enzyme, T1 lipase. The melting temperatures $\left(T_{m}\right)$ of the three proteins were different with variant unfolded fractions. All of the proteins started to unfold at $60{ }^{\circ} \mathrm{C}$ at different melting temperature. These differences might be due to loss of the protein secondary structure followed by an increase in the unordered conformations of the proteins. T1 lipase (circle), K344R lipase (triangle) and D311E lipase (square) showed different $T_{m}$, which were $68.52{ }^{\circ} \mathrm{C}, 68.54{ }^{\circ} \mathrm{C}$ and 
$70.59{ }^{\circ} \mathrm{C}$, respectively. D311E lipase was the most stable among the three proteins. D311E lipase involved a different portion of the loop to significantly strengthen the interaction compared to mutant $\mathrm{K} 344 \mathrm{R}$, in which the interaction was found solely inside the loop region.

Figure 2. Denatured protein analysis by circular dichroism. $T_{m}$ of T1 lipase (blue) was at $\sim 68.52{ }^{\circ} \mathrm{C}, \mathrm{K} 344 \mathrm{R}$ lipase (green) at $\sim 68.54{ }^{\circ} \mathrm{C}$ and D311E lipase (red) at $\sim 70.59^{\circ} \mathrm{C}$.

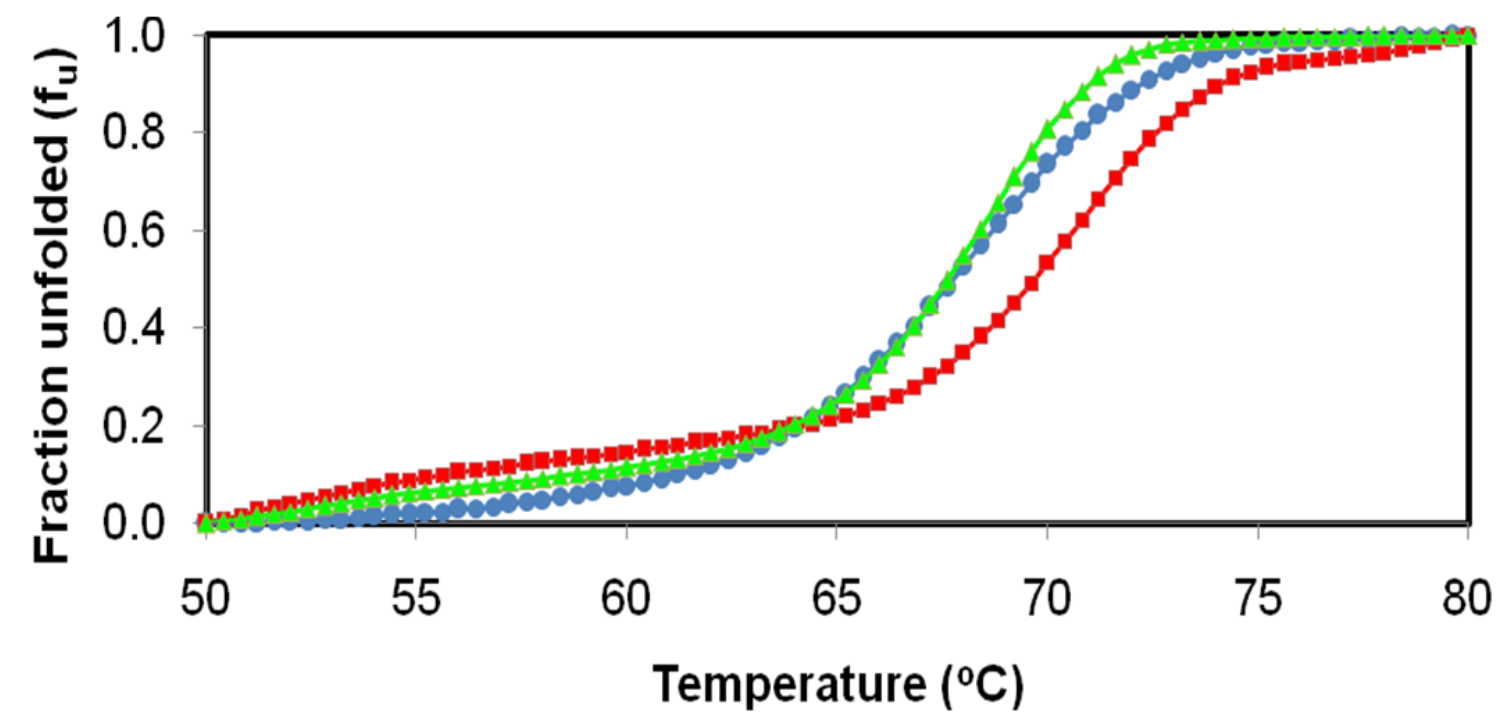

Changes in protein stability were determined upon making point mutations with I-mutant 2.0. The mutants D311E (exposed residue) and K344R (moderately exposed residue) showed increased and decreased stability, respectively. Despite a reduction of one ion pair, networks formed by the ion pair and the hydrogen bond between loops were stronger than the interactions located inside the loop of the crystal structure of T1 lipase. As suggested by [13] Derewenda et al., the converted structure is stabilized once proper inter-subunit bridges are formed. Based on Figure 2, the K344R mutant had the same $T_{m}$ as the wild-type. The ion pair introduced did not affect the thermal stability.

The CD spectra (molecular ellipticity) of T1 lipase and its mutants were analyzed as a function of temperature at $220 \mathrm{~nm}$ to monitor the transition of $\alpha$-helical structures to disordered structures. As shown in Figure 3, there are no significant structural changes observed for T1 lipase and its mutants. The result indicated that the mutation at loop regions did not change the conformation of the proteins. However, there is an increase of $T_{m}$ for mutant D311E as compared to wild-type T1 lipase and another mutant K344R. When a protein starts to unfold due to heating, the process will go through an intermediate state, thus the free energy change $(\Delta G)$ at equilibrium was zero. As a consequence, the T1 lipase, D311E and $\mathrm{K} 344 \mathrm{R}$ showed a melting temperature, $T_{m}$ of $68.52{ }^{\circ} \mathrm{C}(341.52 \mathrm{~K}), 70.59{ }^{\circ} \mathrm{C}(343.59 \mathrm{~K})$ and $68.54{ }^{\circ} \mathrm{C}(341.54 \mathrm{~K})$, respectively with the unfolding enthalpy $(\Delta H)$ and entropy $(\Delta S)$ as listed in Table 2. 
Figure 3. CD spectra of T1 lipase (green) and mutant D311E (blue) and K344R (red).
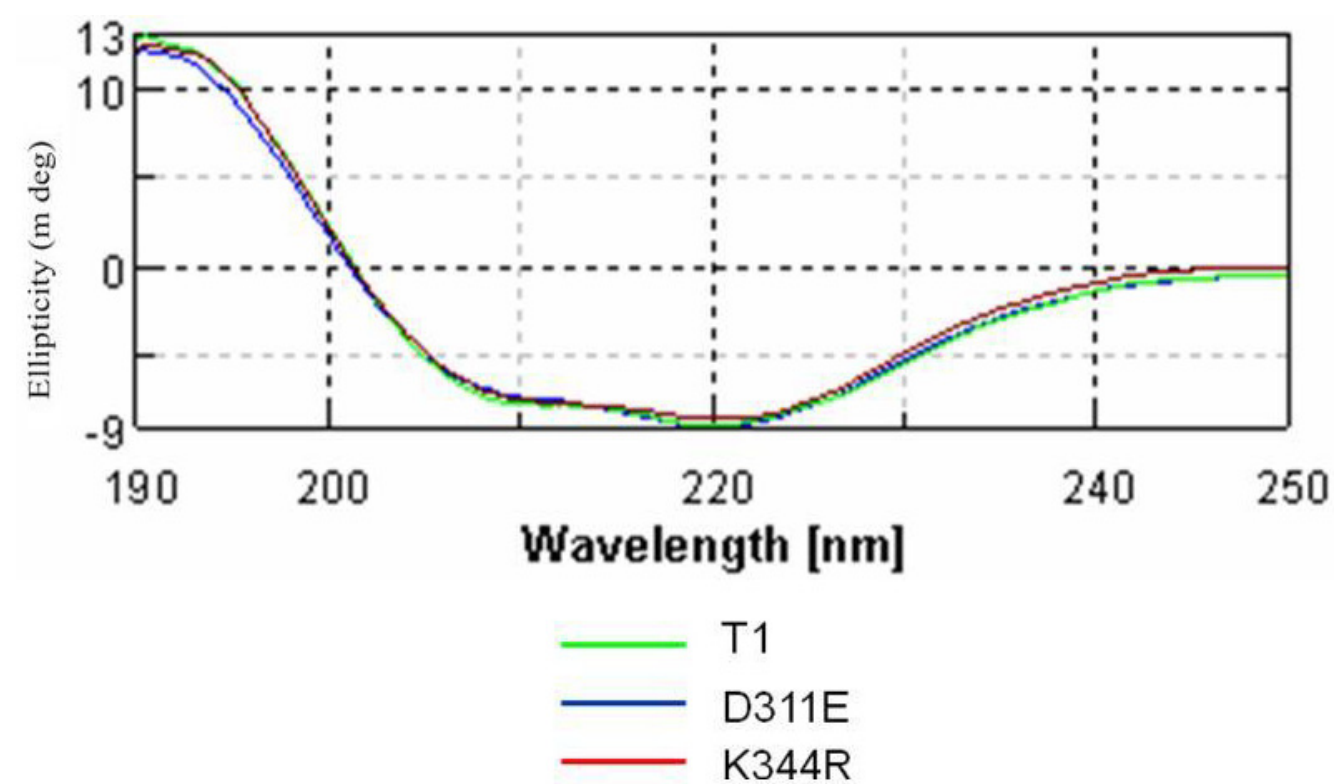

Table 2. Thermodynamic parameters for the thermal denaturation transition of T1 lipase and its mutants as calculated from CD data.

\begin{tabular}{ccc}
\hline Strain & $\boldsymbol{\Delta S}(\mathbf{k J} / \mathbf{m o l} / \mathbf{K})$ & $\boldsymbol{\Delta H}(\mathbf{k J} / \mathbf{m o l})$ \\
\hline T1 & -1.22 & -417.34 \\
D311E & -1.88 & -645.98 \\
K344R & -1.83 & -625.30 \\
\hline
\end{tabular}

Although the prediction of K344R mutant stability that was generated by the I-Mutant 2.0 software showed a decrease in stability (Table 1), the experimental CD results showed no change in stability. Because the prediction and CD data indicated that D311E was a better enzyme than K344R; D311E was chosen for structural analysis.

\subsection{Effect of Temperature on D311E and T1 Lipase Activity and Stability}

Both D311E and $\mathrm{T} 1$ had an optimum temperature of $70{ }^{\circ} \mathrm{C}$ (Figure 4A) for stability as shown in Figures $4 \mathrm{~B}, \mathrm{C}$, the $t_{1 / 2}$ of $\mathrm{T} 1$ lipase at $60{ }^{\circ} \mathrm{C}$ and $70{ }^{\circ} \mathrm{C}$ was $30 \mathrm{~min}$ and $10 \mathrm{~h}$, respectively. However, the mutant D311E lipase enhanced the temperature effect as compared to the wild-type. The $t_{1 / 2}$ of D311E lipase at $60{ }^{\circ} \mathrm{C}$ and $70{ }^{\circ} \mathrm{C}$ was $110 \mathrm{~min}$ and up to $12 \mathrm{~h}$, respectively. A single mutation of LST-03 lipase from Pseudomonas aeruginosa LST-03 was found to stabilize the lipase by inducing structural changes including the formation of a salt bridge and hydrogen bonds [24]. Moreover, [25] Vetriani et al. suggest that ion-pair networks may provide a general strategy for manipulating enzyme thermostability of multisubunit enzymes. This shows that the introduction of ion pair stabilized the T1 lipase at high temperature. Most importantly, the ability to retain activity and stability at high temperatures demonstrates great potential in industrial fields. 
Figure 4. Effect of temperature on D311E and T1 lipase activity and stability. (A) The optimum temperature of D311E and T1 lipase; (B) Effect of temperature on lipase stability, pre-incubated at $70{ }^{\circ} \mathrm{C}$; (C) Effect of temperature on lipase stability, pre-incubated at $60{ }^{\circ} \mathrm{C}$.

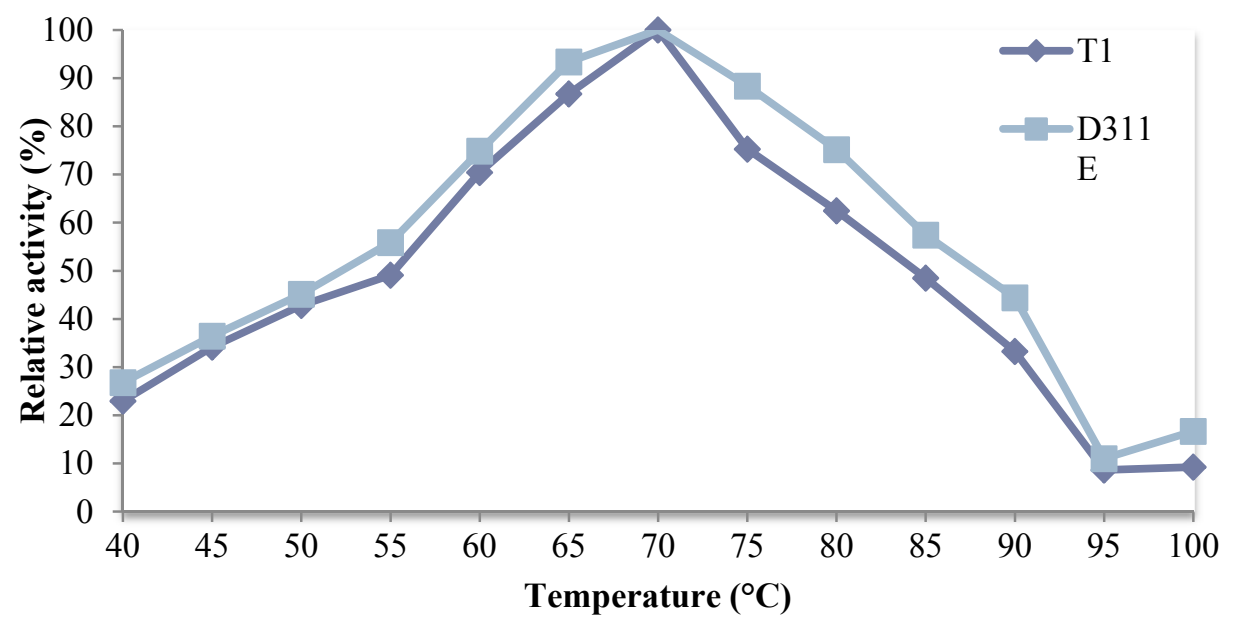

(A)

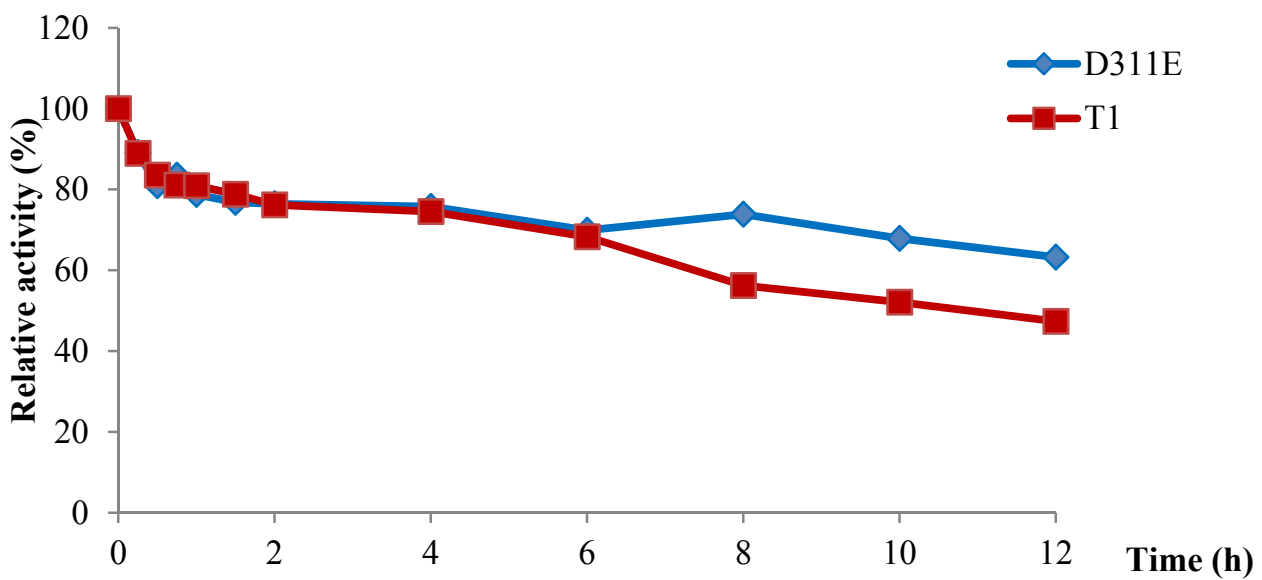

(B)

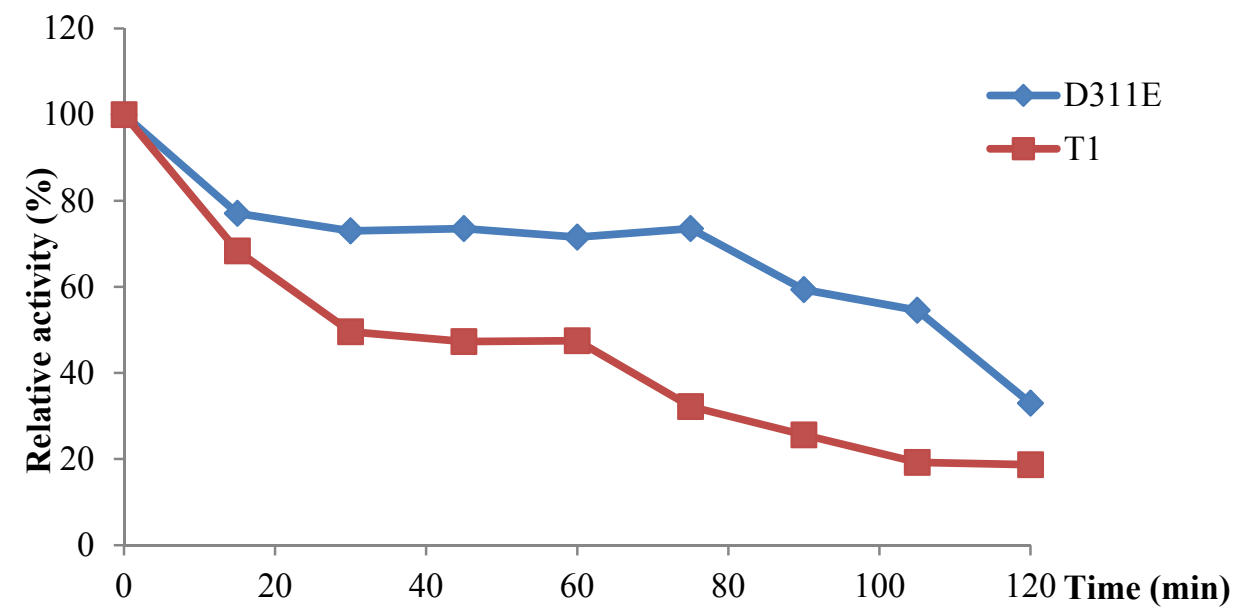

(C) 


\subsection{Crystallization of D311E lipase}

The purified D311E lipase was assayed using the colorimetric assay [26], and the purity was checked using SDS-PAGE and native PAGE [27]. D311E lipase was successfully purified to 10.56-fold with $15.71 \%$ of yield using a serial-step chromatographic strategy (Table 3). The amount of the total protein $(\mathrm{mg})$ and total activity (U) of D311E lipase were two times higher than the wild-type (Data not shown). Figure 5 shows the crude sample D311E lipase (A) loaded on SDS-PAGE as compared to the crude of wild-type T1 lipase (B). The estimated size (66 kDa) was similar to its predicted molecular weight but the band of D311E lipase was slightly thicker than T1 lipase obtained through SDS-PAGE.

Table 3. Summary of the purification procedure for the thermostable D311E lipase.

\begin{tabular}{lccccc}
\hline $\begin{array}{c}\text { Purification } \\
\text { Steps }\end{array}$ & $\begin{array}{c}\text { Total Activity } \\
(\mathbf{U})\end{array}$ & $\begin{array}{c}\text { Total Protein } \\
(\mathbf{m g} / \mathbf{m L})\end{array}$ & $\begin{array}{c}\text { Specific Activity } \\
(\mathbf{U} / \mathbf{m g})\end{array}$ & $\begin{array}{c}\text { Recovery } \\
\mathbf{( \% )}\end{array}$ & $\begin{array}{c}\text { Purification } \\
\text { Fold }\end{array}$ \\
\hline Crude & $41,609.00$ & 44.88 & 18.54 & 100.00 & 1.00 \\
Affinity 1 & $18,366.50$ & 21.67 & 19.78 & 44.14 & 1.83 \\
Affinity 2 & $12,904.74$ & 19.56 & 36.65 & 31.01 & 1.98 \\
IEX & $6,538.10$ & 3.34 & 195.75 & 15.71 & 10.56 \\
\hline
\end{tabular}

Note: The GST fusion lipase was purified under native condition. Affinity 1 represents Glutathione Sepharose HP, affinity 2 represents Glutathione-Sepharose HP, Glutathione-Sepharose 4FF and Benzamidine FF (high sub) attached in series, whereas IEX represents Q Sepharose FF.

Figure 5. (A) SDS-PAGE (12\%) of crude mutant lipase D311E. M: standard protein markers (kDa); (B) SDS-PAGE (12\%) of crude native T1 lipase. M: standard protein markers.

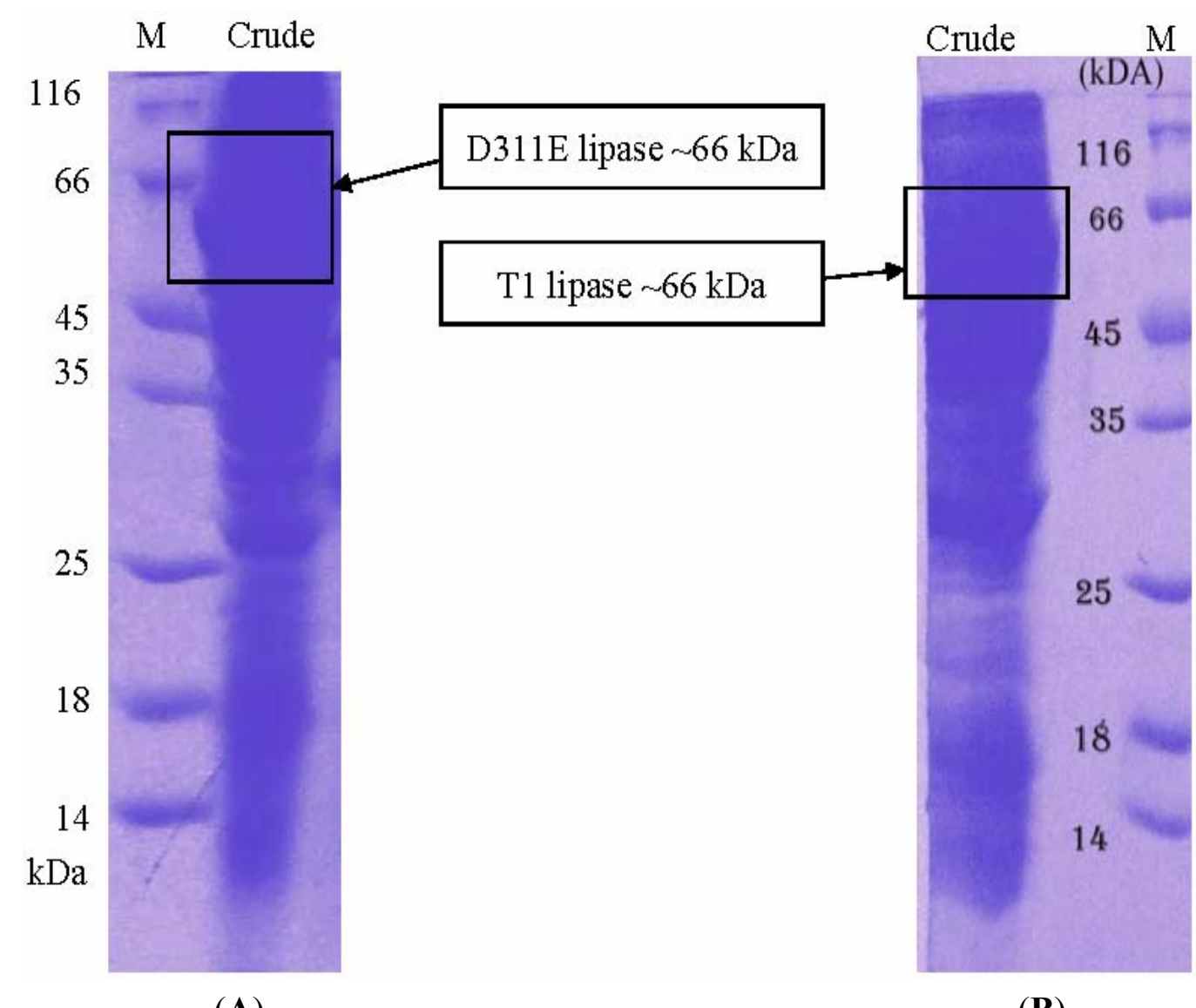

(A)

(B) 
For crystallization, ion exchange chromatography was performed as the final step of purification for D311E lipase. A single band was observed in SDS-PAGE (Figure 6A), estimated to be $43 \mathrm{kDa}$ and native-PAGE (Figure 6B), indicating that this purified D311E lipase was suitable for protein crystallization.

Figure 6. (A) SDS-PAGE (12\%) of mutant lipase D311E. M: standard protein markers (kDa); purified lipase (lane 1 and 2); (B) Single band of D311E lipase on Native PAGE analysis after ion exchange chromatography.

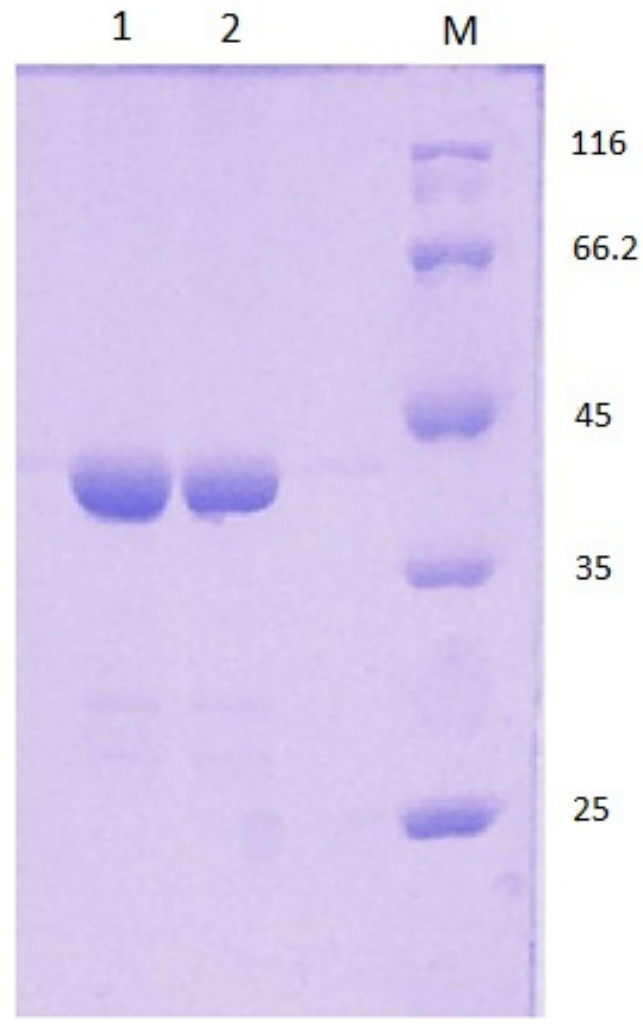

(A)

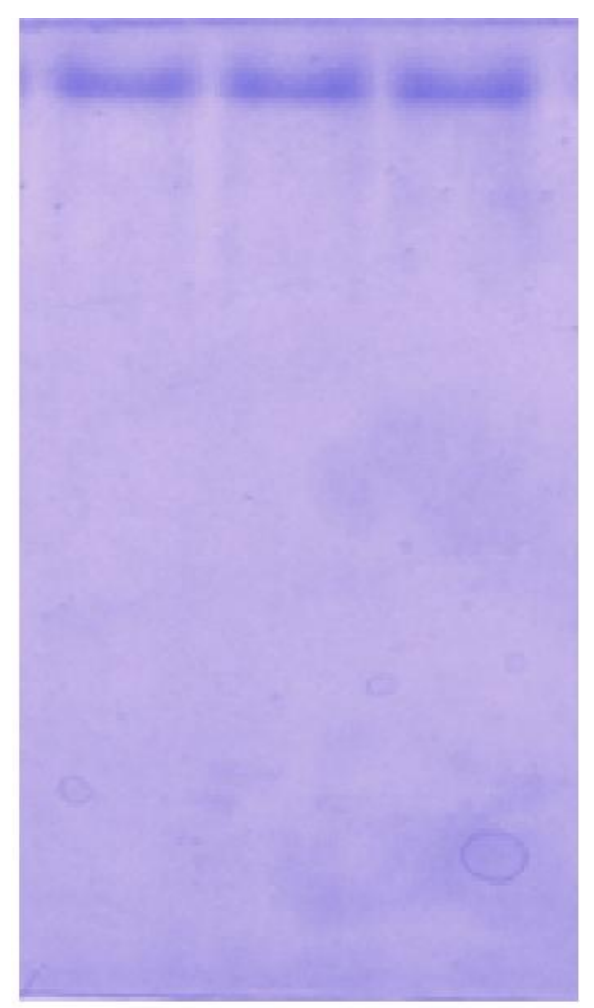

(B)

Optimization of D311E lipase crystallization was conducted and it was found that the best formulation was $0.1 \mathrm{M}$ MES $\mathrm{pH} 5.5,0.1 \mathrm{M}$ sodium phosphate, $0.1 \mathrm{M}$ potassium phosphate, and $1.5 \mathrm{M}$ $\mathrm{NaCl}$ as a precipitant. Crystallization conditions such as $\mathrm{pH}$, protein concentration, precipitant, and temperature were found to affect the quantity, size and quality of the crystal. The crystals were grown using the sitting drop vapor diffusion method. Good quality crystals of D311E lipase were observed after overnight incubation at $20^{\circ} \mathrm{C}$. The size of the crystal reached $0.2 \mathrm{~mm} \times 0.1 \mathrm{~mm} \times 0.1 \mathrm{~mm}$ (Figure 7). 
Figure 7. D311E lipase crystal grown using sitting drop method with $0.1 \mathrm{M}$ MES $\mathrm{pH}$ 5.5, 0.1 M Sodium phosphate, $0.1 \mathrm{M}$ Potassium phosphate, and $1.5 \mathrm{M} \mathrm{NaCl}$ as precipitant reagent.

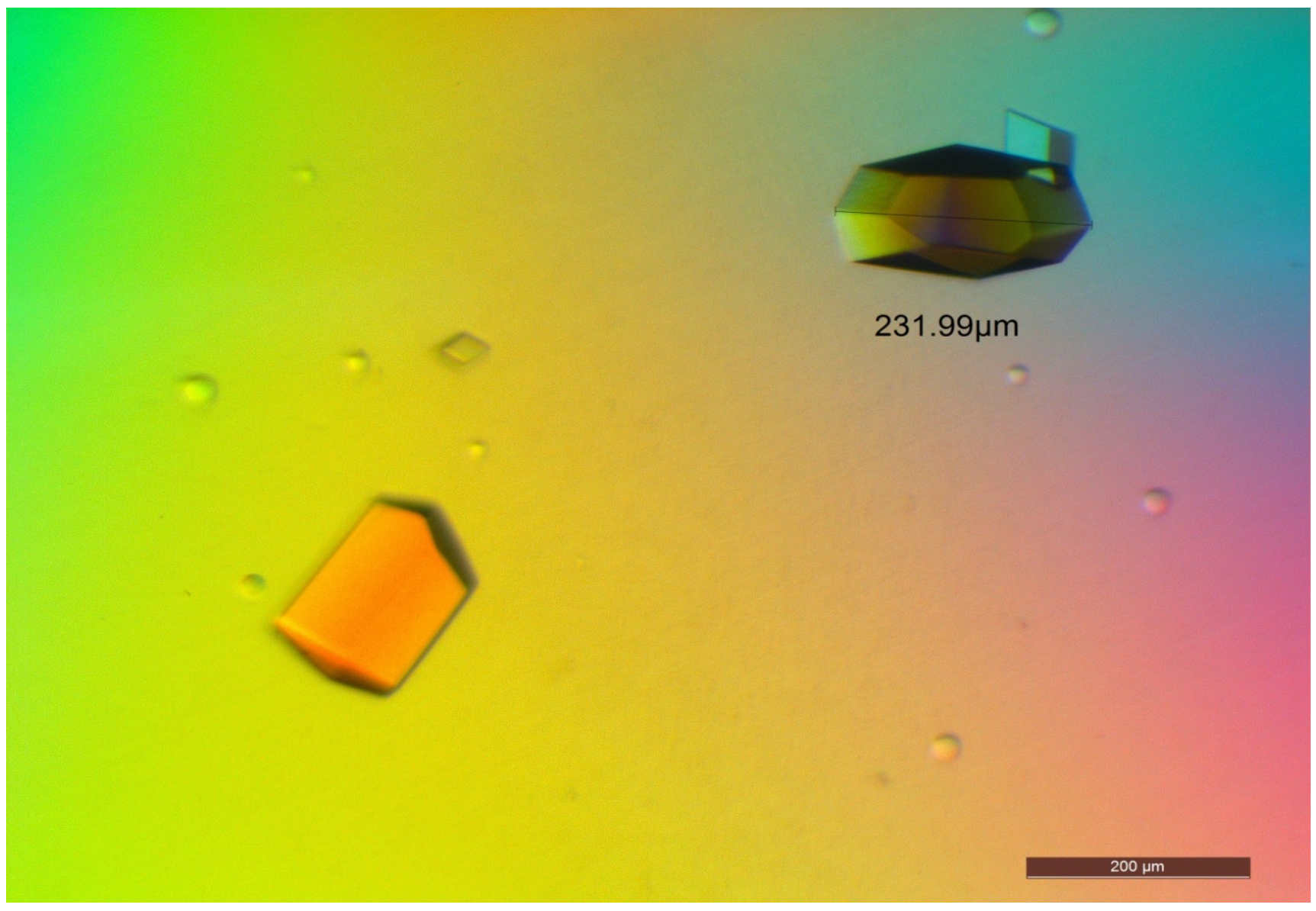

\subsection{X-Ray Data Collection}

The D311E lipase crystal was diffracted at approximately $2.1 \AA$, and the diffraction pattern is shown in Figure 8. X-ray diffraction data for D311E lipase were collected using an in-house X-ray diffractometer. This crystal belonged to the $C 2$ space group with the unit-cell parameters $a=117.32 \AA$, $b=81.16 \AA$ and $c=100.13 \AA$. Data processing statistics are shown in Table 4.

Generally, the volume of the crystal will affect the completeness (\%) and the signal-to-noise ratio. The Matthews coefficient for the D311E lipase was $2.75 \AA^{3} \mathrm{Da}^{-1}$ [28], and the crystals consisted of $55.33 \%$ solvent, which was in the range of $40-60 \%$ as stated in [29] with certain exceptions. A higher solvent content in a crystal significantly correlated with decreasing resolution.

Compared to BTL2 lipase, this crystal lipase was solved in closed conformation at high resolution (2.1 $\AA$ ) using in-house X-ray diffractometer. In contrast, the diffraction data for BTL2 lipase crystal was collected using synchrotron radiation source at $2.2 \AA[15]$. 
Figure 8. Diffraction patterns of thermostable mutant lipase D311E. The resolution is $\sim 2.1 \AA$ at the edge with starting position; distance: $50.00 \mathrm{~mm}, 2$ theta: $22.00^{\circ}$, Omega: 31.64 ${ }^{\circ}$, Phi: $271.48^{\circ}$, Chi: $-30.01^{\circ}$ and ending position; distance: $50.00 \mathrm{~mm}$, 2theta: 22.00․, Omega: $31.64^{\circ}$, Phi: $271.98^{\circ}$, Chi: $-30.01^{\circ}$.

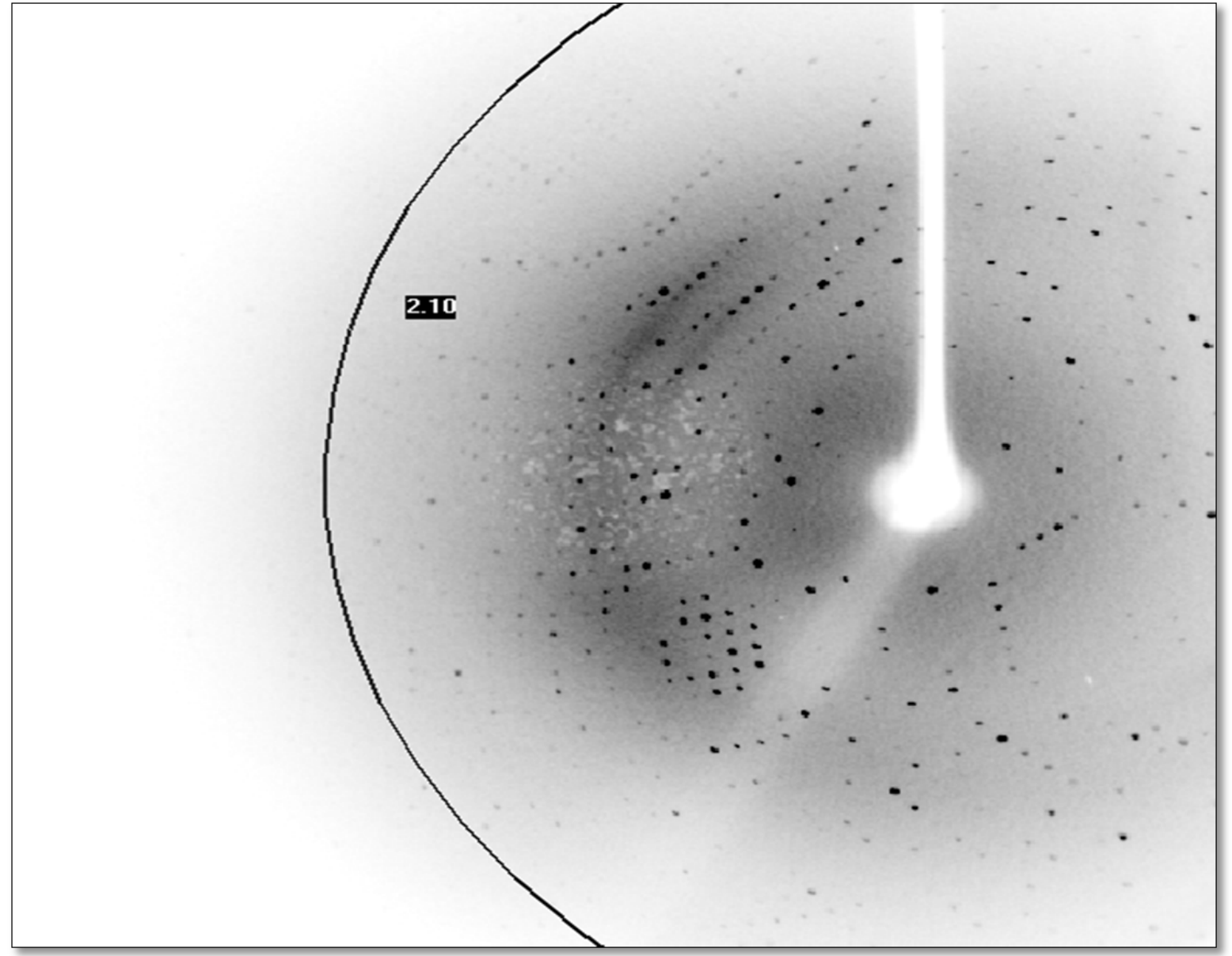

Table 4. Summary of the crystallographic data.

\begin{tabular}{lc}
\hline & D311E \\
\hline Unit cell parameters & $a=117.32 \AA, b=81.16 \AA, c=100.14 \AA$ \\
& $\mathrm{a}=90.00{ }^{\circ} \mathrm{C}, \mathrm{a}=96.49{ }^{\circ} \mathrm{C}, \tilde{\mathrm{a}}=90.00{ }^{\circ} \mathrm{C}$ \\
Space group & $C 2$ \\
Wavelength $(\AA)$ & 1.54 \\
Resolution range $(\AA)$ & $37.57-2.1(2.2-2.1)$ \\
No. of observed reflections & 249,261 \\
No. of unique reflections & 88,705 \\
Redundancy $(\%)$ & $2.93(2.15)$ \\
Completeness $(\%)$ & $96.9(91.4)$ \\
Mean I/ó (I) & $10.02(4.01)$ \\
Molecules per asymmetric units & 2 \\
$V_{\mathrm{M}}\left(\AA^{3} \mathrm{Da}^{-1}\right)$ & 2.75 \\
Solvent content $(\%)$ & 55.33 \\
$R_{\text {merge }}(\%)$ & $8.33(19.46)$ \\
\hline
\end{tabular}


Table 4. Cont.

\begin{tabular}{lc}
\hline & D311E \\
\hline Refinement statistics & \\
\hline Structure solution method & Molecular replacement \\
Resolution (High) & 2.1 \\
Resolution (Low) & 33.2 \\
Cut-off sigma (F) & 0.0 \\
Number of reflections (Observed) & 50139 \\
Number of reflections (R-free) & 2677 \\
Percent reflections (Observed) & 96.8 \\
R-factor (Observed) & 0.15 \\
R-work & 0.155 \\
R-free & 0.212 \\
\hline
\end{tabular}

\subsection{Structural Analysis}

The X-ray structure of D311E lipase $(2.1 \AA)$ showed a typical $\alpha / \beta$ hydrolase canonical fold consisting of $11 \beta$-strands and $13 \alpha$-helices. The Ser113, Asp317 and His358 were assigned as the catalytic triad. The distance of charged side chains near the mutation site were measured to verify the possible ion pair formation. In D311E lipase, the ion pair network was composed of five amino acid residues (Arg 274, Thr 278, Gly 279, Arg 303 and Glu 311) connected by seven ion pairs. The comparison of the number of charged residues involved in ion pairs was made between D311E lipase with T1 lipase (Table 5). There were obvious differences in the ion pair distances at the mutation site. In D311E lipase, the distances from these ion pairs were between $2.5 \AA$ and $5.2 \AA$. In contrast, the distances of ion pair involved in T1 lipase were longer than those in D311E lipase. On average, the distances indicated a strong interaction, which is around $2.0 \AA$ to $3.0 \AA$. To date, there is no ion pair introduced at position D311 in lipase structure.

Table 5. The number of charged residues involved in ion pairs of $\mathrm{T} 1$ lipase and D311E lipase.

\begin{tabular}{|c|c|c|c|c|c|}
\hline & Residue & Position & Residue & Position & Distance $(\AA)$ \\
\hline \multirow[t]{5}{*}{$\mathrm{T} 1$} & Asp 311 & OD2 & Arg 274 & $\mathrm{NH} 2$ & 7.0 \\
\hline & & & Arg 274 & $\mathrm{NE}$ & 7.0 \\
\hline & & & Arg 274 & NH1 & 8.8 \\
\hline & & & Thr 278 & $\mathrm{O}$ & 4.8 \\
\hline & & & Gly 279 & $\mathrm{O}$ & 4.9 \\
\hline \multirow[t]{7}{*}{ D311E } & Glu 311 & OE1 & Arg 303 & NH2 & 5.2 \\
\hline & & & Arg 274 & $\mathrm{NH} 2$ & 3.8 \\
\hline & & OE2 & Arg 274 & NH2 & 2.5 \\
\hline & & & Arg 274 & $\mathrm{NE}$ & 3.7 \\
\hline & & & Arg 274 & NH1 & 4.1 \\
\hline & & & Thr 278 & $\mathrm{O}$ & 3.7 \\
\hline & & & Gly 279 & $\mathrm{O}$ & 3.4 \\
\hline
\end{tabular}


The Glu 311 and Gly 279 were connected by one hydrogen bond and linked to each other at an $\alpha$-helix and a band region. This substitution affected the structural stability, which made the inter-connection of the D311E lipase (Figure 9). A significant increase in the number of ion pairs has been reported for most structures of thermostable proteins [30]. Furthermore, the ion pair interactions contributed to the forces that held the monomers together. For the glutamate dehydrogenase (GDH) from hyperthermophiles, the intersubunit ion pairs are involved in maintaining a stable structure [13]. In addition, the formation of ion-pair networks on the surface of the protein subunits that are buried at the interdomain and intersubunit interfaces may represent a major stabilizing feature that is associated with the adaptation of enzymes to extreme temperatures [31].

Figure 9. Snapshoot of ion pair interaction formation of D311E lipase crystal structure at residue between Glu311 and four residues (Arg 274, Thr 278, Gly 279 and Arg 303).

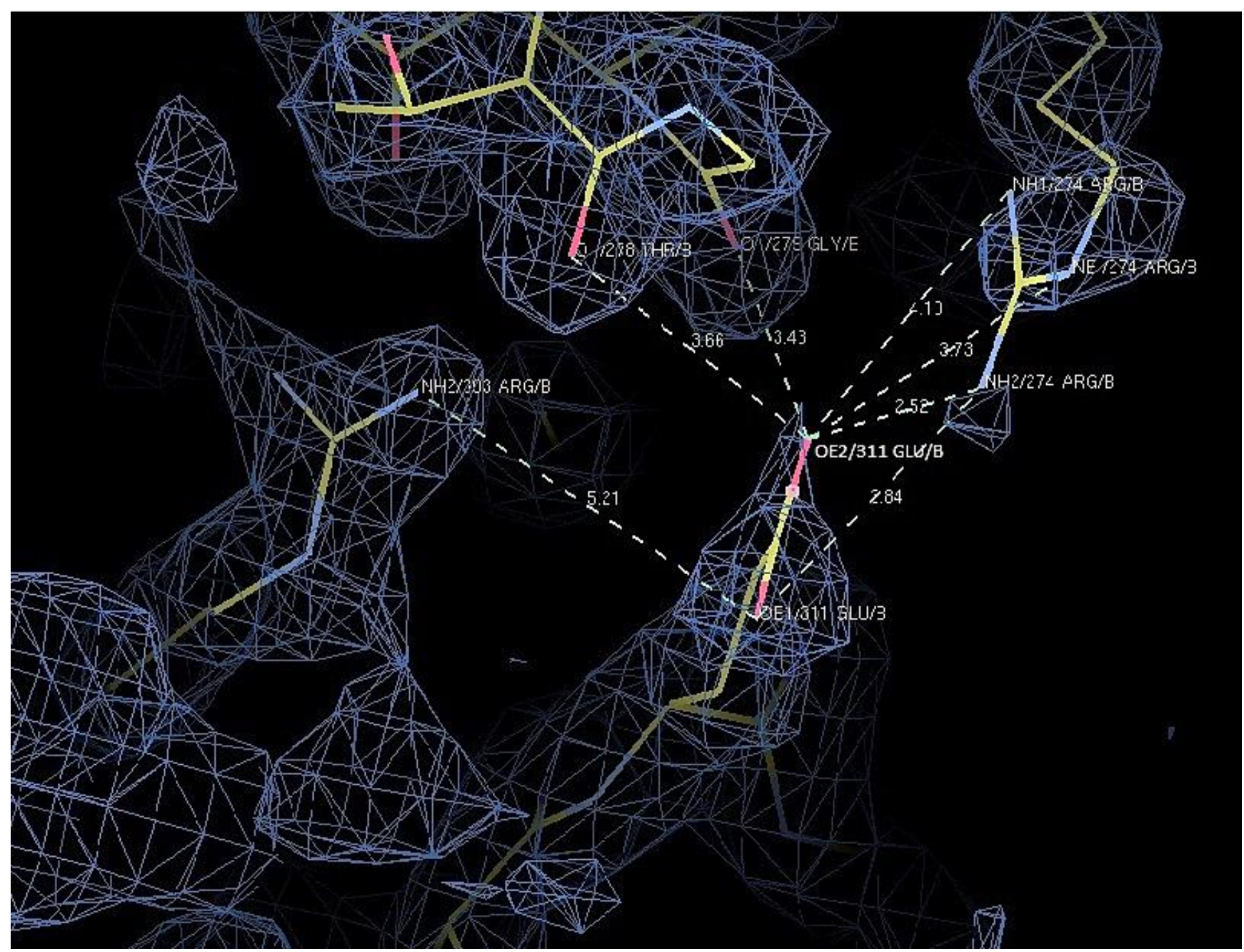

* The generated 2Fo-Fc electron-density maps with 1.0 sigma level.

The coordinates of D311E crystal structure was deposited to RCSB Protein Data Bank under PDB ID code 3 UMJ. 


\section{Experimental Section}

\subsection{Site Directed Mutagenesis}

Two mutants were prepared: D311E, in which aspartic acid at position 311 for the inter-loop interaction study was changed to glutamic acid, and K344R, in which lysine at position 344 for the intra-loop interaction studies was mutated into arginine. The mutagenic plasmids constructed using the site-directed mutagenesis systems (Invitrogen) were introduced into the Escherichia coli BL21 (DE3) pLysS. Mutations were visualized and adjusted using Swiss PDB Viewer and the images were constructed using POV-Ray.

\subsection{Prediction of Mutants Stability}

The stability of putative mutants was predicted and performed using computational algorithm tools, namely I-Mutant 2.0. I-Mutant 2.0 is a support vector machine (SVM)-based tool for the automatic prediction of protein stability changes upon single amino acid substitutions [21]. The software computed the predicted free energy change value or sign (DDG), which is calculated from the unfolding Gibbs free energy value of the mutated protein minus the unfolding Gibbs free energy value of the native protein (kcal/mol). A positive DDG value indicates that the mutated protein possesses high stability whereas a negative DDG value indicates less stability of the mutant. A high reliability index (RI) is also important for interpreting the output data.

\subsection{Protein Expression and Purification of T1 Lipase, D311E Lipase and K344R Lipase}

The parental plasmid pGEX/T1S was used as the expression system (Figure 10). E. coli BL21 (DE3) pLysS mutagenic plasmid containing pGEX/T1, pGEX/D311E and pGEX/K344R were grown in Luria-Bertani (LB) medium that was supplemented with $100 \mu \mathrm{g} / \mathrm{mL}$ of ampicillin and $35 \mu \mathrm{g} / \mathrm{mL}$ of chloramphenicol under shaking conditions at $200 \mathrm{rpm}$ and $37{ }^{\circ} \mathrm{C}$. The expression of the lipases was induced using $25 \mu \mathrm{M}$ of isopropyl $\beta$-D-1-thiogalactopyranoside (IPTG) at an $\mathrm{OD}_{600}$ value of approximately $\sim 0.75$. The cultures were grown for $12 \mathrm{~h}$, and the pellets were harvested by centrifugation at $10,000 \mathrm{rpm}$ for $10 \mathrm{~min}$ at $4{ }^{\circ} \mathrm{C}$. The pellets were resuspended with $20 \mathrm{ml}$ of phosphate-buffered saline (PBS, pH 7.4) that was supplemented with $5 \mathrm{mM}$ of dithiothreitol (DTT) and sonicated (output: 2, duty cycle: 30) for $2 \mathrm{~min}$. The crude enzymes were collected by centrifugation at $10,000 \mathrm{~g}$ for $20 \mathrm{~min}$ at $4{ }^{\circ} \mathrm{C}$. Filtered crude enzymes were loaded into a XK 16/20 column packed with $10 \mathrm{ml}$ of Glutathione Sepharose 4 Fast Flow that had been pre-equilibrated with 10 column volumes (CV) of PBS (pH 7.4). The column was then washed with $3 \mathrm{CV}$ of PBS (pH 7.4) and eluted with thrombin cleavage buffer (pH 8). The eluted fusion lipase fractions were pooled and incubated with thrombin enzymes to cleave the glutathione $S$-transferase (GST) tag. The GST tag was removed by applying the digested fusion lipase into second affinity chromatography columns packed with Glutathione Sepharose 4 Fast Flow, GSTrap and Hi-Trap Benzamidine, in which were attached in series [32]. An extra step of purification for D311E was performed to improve the quality of the crystal. 
Figure 10. Schematic diagram of the parental plasmid pGEX/T1S. Expression of the T1, D311E and K344R lipase gene were done as the fusion protein.

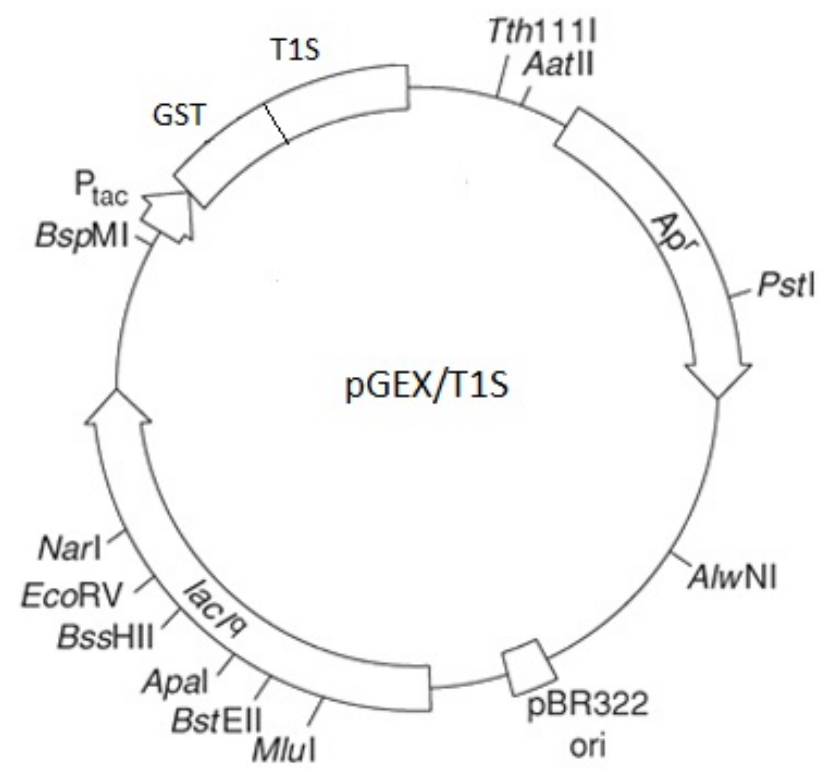

\subsection{Circular Dichroism Spectral Analysis}

All purified lipases in sodium phosphate buffer $(10 \mathrm{mM}, \mathrm{pH} 8.0)$ were analyzed using the spectropolarimeter J-810 (Jasco, Japan) for circular dichroism (CD) spectral analysis. The warm-up periods of $50{ }^{\circ} \mathrm{C}$ to $80^{\circ} \mathrm{C}$ and the wavelength scan of $180 \mathrm{~nm}$ to $250 \mathrm{~nm}$ were considered. The variable temperature measurement of T1, D311E and K344R lipases were performed using $10 \mathrm{~mm}$ cells after determining the $\mathrm{CD}$ value at $220 \mathrm{~nm}$. The warm-up period was $50{ }^{\circ} \mathrm{C}$ to $80{ }^{\circ} \mathrm{C}$, and the step was 1 degree per minute. The wavelength was set to $220 \mathrm{~nm}$. The concentration was $1 \mathrm{mg} / \mathrm{mL}$, and the top of the cell was completely closed using a cap. The data pitch, bandwidth, response, scanning speed, and accumulation were set to be 0.1 degree, $1 \mathrm{~nm}, 8$ seconds, 1 degree per minute and 8 times, respectively.

\subsection{Electrophoresis}

SDS-PAGE and native PAGE were carried out on 12\% running gel [27]. A broad range of protein standard (MBI Fermentas, St Leon-Rot, Germany) was used as a molecular mass marker.

\subsection{Effect of Temperature on D311E and T1 Lipase Activity and Stability}

The effect of temperature on D311E and T1 lipase activity was measured at temperatures ranging from 40 to $100{ }^{\circ} \mathrm{C}$ at $5{ }^{\circ} \mathrm{C}$ intervals for $30 \mathrm{~min}$. The lipase activity was assayed at shaking rate of $200 \mathrm{rpm}$ with olive oil as substrate [24].

Enzyme stability test was conducted by pre-incubating D311E and T1 lipase at $60{ }^{\circ} \mathrm{C}$ and $70{ }^{\circ} \mathrm{C}$ for various times prior to lipase assay at $70{ }^{\circ} \mathrm{C}$ under shaking condition $(200 \mathrm{rpm})$ for $30 \mathrm{~min}$. 


\subsection{Crystallization of D311E Lipase}

A crystallization experiment was set up using the sitting drop vapor diffusion method. The D311E lipase was crystallized using the formulation 21 ( $0.1 \mathrm{M} \mathrm{MES}$ at pH 6.5, 0.1 M sodium phosphate, $0.1 \mathrm{M}$ potassium phosphate and $2.0 \mathrm{M} \mathrm{NaCl}$ ) of the Crystal Screen 2 reagent kit (Hampton Research, UK). The crystallization process was performed by mixing pure protein with the reservoir solution in a ratio of 1:1 $(1.5 \mu \mathrm{L}: 1.5 \mu \mathrm{L})$ using an Oryx8 protein crystallization robot (Douglas Instruments Ltd., UK) and then equilibrated with $50 \mu \mathrm{L}$ of a reservoir solution at $20{ }^{\circ} \mathrm{C}$ for several days. After an overnight incubation, the crystal growth was observed using a stereomicroscope (Leica M165C, Germany).

\subsection{X-Ray Data Collection}

A set of X-ray data was obtained using the in-house Bruker X8 PROTEUM biological single crystal 103 diffractometer system with a MICROSTAR microfocus rotating anode generator 104 (Bruker. Germany). A PLATINUM $135 \mathrm{CCD}$ detector was placed at a distance of $50 \mathrm{~mm}$. Prior to performing the diffraction, the crystal was flash-cooled with cryoprotectant $(40 \%$ glycerol and $1.9 \mathrm{M} \mathrm{NaCl})$ to prevent ice crystal formation. The crystal was mounted under a liquid nitrogen flow at $100 \mathrm{~K}$. The resolution data were indexed using PROTEUM and integrated with SAINT. SADABS was used to scale the data, and Xprep was used to determine the space group. The model was further built and refined using Refmac5 [33] and COOT, which is a molecular graphics application for manual model corrections [34].

\section{Conclusions}

In conclusion, the crystal structure of thermostable D311E lipase was solved at $2.1 \AA$. We showed that the introduction of an additional ion pair in the lipase structure increased the stability of the protein at high temperatures. The improved stability of D311E lipase was due to additional inter-loop interactions, which were indicated by the atomic details of D311E lipase with the observed additional ion pair and hydrogen bond interactions.

\section{Acknowledgments}

We would like to thank Marianna Biadene and Naoki Shibata with the data collection and their helpful discussion. This research was supported by the Ministry of Science Technology and Innovation Malaysia (09-05-MGI-GMB001).

\section{References}

1. Togan, V.; Daloglu, A.T. Optimization of 3D trusses with adaptive approach in genetic algorithms. Eng. Struct. 2006, 28, 1019-1027.

2. Gandhi, N.N. Applications of lipase. J. Am. Chem. Soc. 1997, 74, 621-634.

3. Guncheva, M.; Zhiryakova, D. Catalytic properties and potential applications of Bacillus lipases. J. Mol. Catal. B Enzym. 2011, 68, 1-21. 
4. Maciver, B.; McHale, R.H.; Saul, D.J.; Bergquist, P.L. Cloning and sequencing of a serine proteinase gene from a thermophilic Bacillus species and its expression in Escherichia coli. Appl. Environ. Microbiol. 1994, 60, 3981-3988.

5. Petrounia, I.P.; Arnold, F.H. Designed evolution of enzymatic properties. Curr. Opin. Biotechnol. 2000, 11, 325-330.

6. Rodrigues, R.C.; Berenguer-Murcia, Á.; Fernandez-Lafuente, R. Coupling chemical modification and immobilization to improve the catalytic performance of enzymes. Adv. Synth. Catal. 2011, 353, 2216-2238.

7. Ó'Fágáin, C. Enzyme stabilization-Recent experimental progress. Enzym. Microb. Technol. 2003, 33, 137-149.

8. Mateo, C.; Palomo, J.M.; Fernandez-Lorente, G.; Guisan, J.M.; Fernandez-Lafuente, R. Improvement of enzyme activity, stability and selectivity via immobilization techniques. Enzym. Microb. Technol. 2007, 40, 1451-1463.

9. Guerois, R.; Nielsen, J.E.; Serrano, L. Predicting changes in the stability of proteins and protein complexes: A study of more than 1000 mutations. J. Mol. Biol. 2002, 320, 369-387.

10. Zhou, H.; Zhou, Y. Distance-scaled, finite ideal-gas reference state improves structure-derived potentials of mean force for structure. Protein Sci. 2002, 11, 2714-2726.

11. Kearns-Jonker, Mary, Barteneva, N.; Mencel, R.; Hussain, N.; Shulkin, I.; Xu, A.; Yew, M.; Cramer, D. Use of molecular modeling and site-directed mutagenesis to define the structural basis for the immune response to carbohydrate xenoantigens. BMC Immunol. 2007, 8, doi:10.1186/14712172-8-3.

12. Rahman, R.N.Z.R.A.; Fujiwara, S.; Nakamura, H.; Takagi, M.; Imanaka, T. Ion pairs involved in maintaining a thermostable structure of glutamate dehydrogenase from a hyperthermophilic archaeon. Biochem. Biophys. Res. Commun. 1998, 248, 920-926.

13. Derewenda, Z.S.; Sharp, A.M. News from the interface: The molecular structures of triacylglyceride lipases. Trends Biochem. Sci. 1993, 18, 20-25.

14. Sarda, L.; Desnuelle, P. Action de la lipase pancreatique sur les esters en emulsion. Biochim. Biophys. Acta 1958, 30, 513-521.

15. Carrasco-López, C.; Godoy, C.; de las Rivas, B.: Fernández-Lorente, G.; Palomo, J.M.; Guisán, J.M.; Fernández-Lafuente, R.; Martínez-Ripoll, M.; Hermoso, J.A. Activation of bacterial thermoalkalophilic lipases is spurred by dramatic structural rearrangements. J. Biol. Chem. 2009, 284, 4365-4372.

16. Matsumura, H.; Yamamoto, T.; Leow, T.C.; Mori, T.; Salleh, A.B.; Basri, M.; Inoue, T.; Kai, Y.; Rahman, R.N.Z.R.A. Novel cation-pi interaction revealed by crystal structure of thermoalkalophilic lipase. Proteins 2008, 70, 592-598.

17. Tanaka, S.; Igarashi, S.; Ferri, S.; Sode, K. Increasing stability of water-soluble PQQ glucose dehydrogenase by increasing hydrophobic interaction at dimeric interface. BMC Biochem. 2005, 6, doi:10.1186/1471-2091-6-1.

18. Yang, S.; Zhou, L.; Tang, H.; Pan, J.; Wu, X.; Huang, H.; Yuan, Z. Rational design of a more stable penicillin G acylase against organic cosolvent. J. Mol. Catal. B Enzym. 2002, 18, 285-290. 
19. Akanuma, S.; Yamagishi, A.; Tanaka, N.; Oshima, T. Serial increase in the thermal stability of 3-isopropylmalate dehydrogenase from Bacillus subtilis by experimental evolution. Protein Sci. 1998, 7, 698-705.

20. Bauer, D.C.; Bodén, M.; Their, R.; Gillam, E.M. STAR: Predicting recombination sites from amino acid sequence. BMC Bioinform. 2006, 7, doi:10.1186/1471-2105-7-437.

21. Capriotti, E.; Fariselli, P.; Casadio, R. I-Mutant2.0: Predicting stability changes upon mutation from the protein sequence or structure. Nucleic Acids Res. 2005, 33, 306-310.

22. Kabsch, W.; Sander, C. Dictionary of protein secondary structure: Pattern of hydrogen-bonded and geometrical features. Biopolymers 1983, 22, 2577-2637.

23. Capriotti, E.; Altman, R.B. Improving the prediction of disease-related variants using protein three-dimensional structure. BMC Bioinform. 2011, 12, doi:10.1186/1471-2105-12-S4-S3.

24. Kawata, T.; Ogino, H. Amino acid residues involved in organic solvent-stability of the LST-03 lipase. Biochem. Biophys. Res. Commun. 2010, 400, 384-388.

25. Vetriani, C.; Maeder, D.L.; Tolliday, N.; Yip, K.S.-P.; Stillman, T.J.; Britton, K.L.; Rice, D.W.; Klump, H.H.; Robb, F.T. Protein thermostability above $100 \hat{\mathrm{A}}{ }^{\circ} \mathrm{C}$ : A key role for ionic interactions. Proc. Natl. Acad. Sci. USA 1998, 95, 12300-12305.

26. Kwon, D.; Rhee, J. A simple and rapid colorimetric method for determination of free fatty acids for lipase assay. J. Am. Chem. Soc. 1986, 63, 89-92.

27. Laemmli, U.K. Cleavage of structural proteins during the assembly of the head of bacteriophage T4. Nature 1970, 227, 680-685.

28. Matthews, B.W. Solvent content of protein crystals. J. Mol. Biol. 1968, 33, 491-497.

29. Crick, F.; Kendrew, J. X-ray analysis and protein structure. Adv. Protein Chem. 1957, 12, 133-214.

30. Voorhost, W.G.B.; Warner, A.; de Vos, W.M.; Siezen, R.J. Homology modeling of two subtilisin-like serine protease from the hyperthermophilic archaea Pyrococcus furiosus and Thermococcus stetteri. Protein Eng. 1997, 10, 905-914.

31. Yip, K.S.P.; Stillman, T.J.; Britton, K.L.; Artymiuk, P.J.; Baker, P.J.; Sedelnikova, S.E.; Engel, P.C.; Pasquo, A.; Chiaraluce, R.; Consalvi, V.; Scandurra, R.; Rice, D.W. The structure of Pyrococcus furiosus glutamate dehydrogenase reveals a key role for ion-pair networks in maintaining enzyme stability at extreme temperatures. Structure 1995, 3, 1147-1158.

32. Leow, T.C.; Salleh, A.B.; Basri, M.; Rahman, R.N.Z.R.A. A thermoalkaliphilic lipase of Geobacillus sp. T1. Extremophiles 2007, 11, 527-535.

33. Murshudov, G.N.; Vagin, A.A.; Dodson, E.J. Refinement of macromolecular structures by the maximum-likelihood method. Acta Crystallogr. D 1997, 53, 240-255.

34. Emsley, P.; Cowtan, K. Coot: Model-building tools for molecular graphics. Acta Crystallogr. D 2004, 60, 2126-2132.

(C) 2012 by the authors; licensee MDPI, Basel, Switzerland. This article is an open access article distributed under the terms and conditions of the Creative Commons Attribution license (http://creativecommons.org/licenses/by/3.0/). 